\title{
Gastric Adenosquamous Carcinoma
}

National Cancer Institute

\section{Source}

National Cancer Institute. Gastric Adenosquamous Carcinoma. NCI Thesaurus. Code C5474.

A carcinoma that arises from the stomach and is characterized by the presence of malignant cells with glandular and squamous differentiation. 